\title{
Determinação de esteróides androgênicos anabólicos em urina por cromatografia gasosa acoplada à espectrometria de massas
}

\author{
Daniel Rossi de Campos ${ }^{1}$, Mauricio Yonamine ${ }^{1 *}$, Maria Janieire de Nazaré Nunes Alves², \\ Regina Lucia de Moraes Moreau ${ }^{1}$
}

${ }^{1}$ Laboratório de Análises Toxicológicas, Departamento de Análises Clínicas e Toxicológicas, Faculdade de Ciências Farmacêuticas, Universidade de São Paulo, ${ }^{2}$ InCor-Instituto do Coração, Hospital das Clínicas, Faculdade de Medicina, Universidade de São Paulo

*Correspondência:

Mauricio Yonamine

Laboratório de Análises Toxicológicas

Faculdade de Ciências Farmacêuticas USP

Av. Prof. Lineu Prestes, 580 B13B 05508-900-São Paulo-Brasil

E-mail:yonamine@usp.br
Esteróides androgênicos anabólicos (EAA) são substâncias naturais, sintéticas ou semi-sintéticas derivadas da testosterona, utilizadas em atividades esportivas com o objetivo de melhorar o desempenho fisico pelo aumento de massa e força muscular. Apesar de causarem efeitos tóxicos graves, principalmente sobre os sistemas cardiovascular, hepático e neuro-endócrino, os EAA têm sido amplamente utilizados no âmbito esportivo. Desta forma, o presente trabalho teve como objetivo a validação de um método para a determinação de esteróides elou seus produtos de biotransformação em amostras de urina por cromatografia gasosa acoplada à espectrometria de massas (CG-EM). O método baseou-se na hidrólise enzimática de esteróides conjugados, no emprego da extração líquido-líquido e na derivação do extrato para posterior análise por CG-EM, no modo de monitoramento seletivo de ions (SIM). O método validado cumpriu com os princípios de confiança necessários para a determinação de EAA em amostras de urina com a finalidade de controle de dopagem no esporte. Os limites de detecção dos esteróides analizados variaram de 0,5 a $15 \mathrm{ng} / \mathrm{mL}$. Bons valores de precisão (intra e interensaio) também foram obtidos $(C V<11 \%)$. Amostras de voluntários $(n=10)$ que relataram uso de EAA foram submetidas ao método. Pela análise das amostras, foi verificado o uso dos principais esteróides utilizados no âmbito esportivo no Brasil.

\section{INTRODUÇÃO}

O uso de fármacos que proporcionam melhora do desempenho físico permeia a história da humanidade desde o
Unitermos

- Esteróides androgênicos anabólicos

- Dopagem

- Espectrometria de massas/ Cromatografia gasosa
Período Clássico. Os gregos ingeriam cogumelos, pois acreditavam que esses poderiam melhorar o desempenho de atletas em competições. Os gladiadores romanos utilizavam certos estimulantes para atenuar a fadiga. Entretanto, somen- 
te em 1967, o uso de substâncias ergogênicas foi oficialmente proibido no esporte pelo Comitê Olímpico Internacional (COI); a lista de substâncias de uso proibido incluía fármacos estimulantes e narcóticos analgésicos. Posteriormente, em 1974, previamente aos Jogos Olímpicos de Montreal (1976), os esteróides androgênicos anabólicos (EAA) foram incluídos na lista de substâncias proibidas devido ao advento da técnica analítica capaz de detectar tais substâncias em amostras biológicas, o radioimunoensaio (Yesalis, 2000; De Rose, Nóbrega, 2004). No início da década de 80, a cromatografia gasosa acoplada à espectrometria de massas (CG-EM) surge como a técnica analítica de escolha para a detecção e quantificação de EAA em programas de controle da dopagem no esporte. Também, em 1983, foi estabelecida a razão Testosterona/Epitestosterona urinária maior que $6(\mathrm{~T} / \mathrm{E}>6)$ para a constatação do uso de ésteres de testosterona por atletas e esportistas (Van de Kerkhof et al., 2000).

Na atualidade, os EAA são utilizados intensamente pela comunidade esportiva com o objetivo de aumentar a massa muscular e a resistência física, apesar da literatura internacional apresentar dados que evidenciam seus efeitos tóxicos, principalmente sobre os sistemas cardiovascular, hepático e neuro-endócrino. Estudos como os de Hurley, Seals, Ehsani. (1984) demonstraram alterações significativas no perfil lipoprotéico (razão LDL/HDL) de usuários de esteróides. Carcinomas hepato-celulares, colestases e hepatites foram descritos por Pärssinen e Seppala (2002) e alterações nas enzimas hepáticas foram observadas por Lenders et al. (1988) e Urhausen, Torsten, Wilfried (2003). Atletas do sexo masculino, usuários de esteróides, também apresentam um decaimento dos níveis séricos de testosterona, em função da supressão do eixo hipotalâmico-hipofisário, resultando em atrofia testicular, infertilidade e perda de libido(Torres-Calleja, Gonzalez-Unzaga, Pedrón., 2001; Silva, Yonamine, 2004). O uso contínuo também pode levar ao desenvolvimento do tecido mamário, alteração anatômica denominada ginecomastia (De Luis, Aller, Cuellar, 2001).

Até o presente, a maneira mais eficaz de minimizar a dopagem no esporte tem sido seu controle sistemático pela realização de análises toxicológicas em material biológico fornecido pelo atleta. Este controle tem sido realizado no período das competições ou durante os treinamentos. Nos últimos anos, de acordo com recentes dados estatísticos do COI, cerca de metade das amostras positivas dos laboratórios de controle de dopagem conveniados a essa entidade são de esteróides (Kicman, Gower, 2003).

$\mathrm{Na}$ literatura científica alguns métodos cromatográficos foram propostos para detecção de EAA em urina (Schanzer, Donike, 1993; Ayotte, Goudreault, Chanlebois, 1996; Özer, Temizer, 1997; Schanzer, 1998; Yoon, Lee, 2001; Marcos et al., 2002). No presente trabalho, um método analítico por GC-MS para a determinação de EAA e/ou seus produtos de biotransformação em amostras de urina foi validado de acordo com os guias internacionais e nacionais que norteiam as normas de boas práticas laboratoriais (World Anti-Doping Agency, 2003a; ANVISA, 2003).

\section{MATERIAL E MÉTODOS}

\section{Soluções-padrão}

Soluções-padrão de testosterona e epitestosterona, na concentração de $1 \mathrm{mg} / \mathrm{mL}$ em metanol, foram gentilmente cedidas pelo Prof. Dr. Franz T. Delbeke (Labo Farmacologie en Toxicologie der Huisdieren, Faculteit Diergeneeskunde, Belgium). Soluções-padrão de 19noretiocolanolona e 19-norandrosterona (produtos de biotransformação da nandrolona), 3-hidroxiestanozolol e 16beta-hidroxiestanozolol (produtos de biotransformação do estanozolol), 17-alfa-metil-5-beta-androstano-3-alfa-17beta-diol e 17-alfa-metil-5-alfa-androstano-3-alfa-17-betadiol (produtos de biotransformação da metiltestosterona), 9alfa-fluoro-17-alfa-metil-4-androsteno-3-alfa-6-beta-11beta-tetrol e 9-alfa-fluoro-18-nor-17,17-dimetilandrostan4,13-dieno-11-beta-ol-3-ona (produtos de biotransformação da fluoximesterona), 17-alfa-etil-5-beta-estrano-3-alfa-17beta-triol (produto de biotransformação da noretandrolona), oximesterona, oxandrolona e metenolona, na concentração de $1 \mathrm{mg} / \mathrm{mL}$ em metanol, foram obtidas da Radian International (Austin, EUA). Metiltestosterona (padrão interno) também foi obtida da Radian International.

\section{Reagentes}

Metanol, éter-t-butilmetílico, bicarbonato de sódio, carbonato de potássio e ácido clorídrico foram de grau p.a. obtidos da Merck (Darmstadt, Alemanha). Iodeto de amônio foi obtido da Fluka (Buchs, Suiça). $N$-metiltrimetilsilil-trifluoroacetamida (MSTFA) e enzima betaglicuronidase (E. coli) foram obtidas da Sigma (St. Louis, EUA). Etanotiol foi obtido da Aldrich (Milwaukee, EUA).

\section{Amostras de urina de voluntários}

Amostras de urina de voluntários $(\mathrm{n}=10)$, que relataram uso de esteróides anabólicos, foram obtidas de indivíduos adultos (acima de 21 anos), do sexo masculino, recrutados pelo Laboratório de Fisiologia do Exercício e Reabilitação Cardíaca - InCor/FMUSP. A coleta das amostras foi aprovada pelo Comitê de Ética do InCor (processo SDC 2246/03/40). 


\section{Preparo das amostras}

A preparação das amostras foi realizada de acordo com método modificado de Delbeke, Desmet, Debackere (1995) conforme descrito por Castilho e Nascimento (2003). Em tubos de centrífuga foram pipetados $4 \mathrm{~mL}$ de urina, $2 \mathrm{~mL}$ de tampão fosfato $\mathrm{pH} 6,8$ e $40 \mathrm{ml}$ da enzima betaglicuronidase de E.Coli. Essas soluções foram submetidas à temperatura de $55{ }^{\circ} \mathrm{C}$ por 60 minutos em estufa. Em seguida, foi adicionado $100 \mathrm{mg}$ de tampão sólido $\left(\mathrm{NaHCO}_{3} /\right.$ $\left.\mathrm{K}_{2} \mathrm{CO}_{3} 2: 1\right)$ que levou a $\mathrm{pH}$ 9-10 e em seguida $50 \mathrm{uL}$ de metiltestosterona $-2 \mathrm{ug} / \mathrm{mL}$ (Padrão Interno). As amostras foram submetidas à extração com $10 \mathrm{~mL}$ de éter tercmetilbutílico. Os tubos foram agitados por 15 minutos e centrifugados por 5 minutos a $350 \mathrm{~g}$. Os sobrenadantes foram retirados e colocados em um béquer contendo sulfato de sódio anidro e transferidos para frascos previamente silanizados, os quais foram submetidos a fluxo de nitrogênio em bloco de aquecimento a $40^{\circ} \mathrm{C}$. A derivação foi realizada com $40 \mathrm{uL}$ do agente de derivação (MSTFA/etanotiol/ $\mathrm{NH}_{4}$ I) por 120 minutos a $80^{\circ} \mathrm{C}$ no bloco de aquecimento. Do extrato final, $2 \mathrm{~mL}$ foram injetados no sistema GC-MS.

\section{Cromatografia gasosa acoplada à espectrometria de massas}

A análise cromatográfica foi realizada em um espectrômetro de massas Hewllet Packard (HP), mode- lo 5972, associado a um equipamento de cromatografia gasosa, modelo 6890. A separação cromatográfica foi realizada através de coluna HP Ultra 1 modificada ( $17 \mathrm{~m}$ x 0,22 $\mathrm{mm} \times 0,11 \mu \mathrm{m})$, utilizando-se hélio como gás de arraste. $\mathrm{O}$ injetor foi operado a $270{ }^{\circ} \mathrm{C}$ (modo splitless). A seguinte programação do forno foi utilizada: temperatura inicial de $120{ }^{\circ} \mathrm{C}$ seguido de aumento de $70{ }^{\circ} \mathrm{C} / \mathrm{min}$ até $182^{\circ} \mathrm{C}$, e posterior aumento da temperatura de $4{ }^{\circ} \mathrm{C} /$ min até $235^{\circ} \mathrm{C}$ e de $30^{\circ} \mathrm{C} / \mathrm{min}$ até $300{ }^{\circ} \mathrm{C}$. A temperatura final permaneceu por 1 minuto. $\mathrm{O}$ espectrômetro de massas foi operado no modo SIM (Monitoramento Seletivo de Íons) com impacto de elétrons $(70 \mathrm{eV})$. As substâncias detectadas e seus respectivos tempos de retenção e fragmentos monitorados são apresentados na Tabela I.

\section{Limite de detecção (LD) e limite de quantificação (LQ)}

O LD e o LQ foram determinados pelo método empírico de diluições sucessivas com urina contendo os esteróides anabólicos e considerando tal valor como a menor concentração determinável com precisão aceitável, isto é, com coeficiente de variação $(\mathrm{CV})<20 \%$ para o LD e $\mathrm{CV}<10 \%$ para o LQ. Sua determinação foi realizada por meio de seis replicatas. O LD e o LQ deveriam ainda satisfazer os seguintes critérios: tempo de retenção relativo menor que $1 \%$ em relação ao calibrador (amostra adicionada com $100 \mathrm{ng} / \mathrm{mL}$ dos esteróides) e razão de íons dentro de 20\% (World Anti-Doping Agency, 2003b).

TABELA I - Esteróides androgênicos anabólicos e parâmetros de detecção por espectrometria de massas

\begin{tabular}{|c|c|c|c|c|}
\hline & Esteróide androgênico anabólico & TR (min) & $\begin{array}{l}\text { Janela de } \\
\text { detecção (min) }\end{array}$ & Íons monitorados \\
\hline 1 & 19-norandrosterona & 9,382 & $8,0-11,0$ & $315,405,420$ \\
\hline 2 & 19-noretiocolanolona & 10,165 & & $315,405,420$ \\
\hline 3 & 17-alfa-metil-5-alfa-androstano-3-alfa-17-beta-diol & 12,002 & $11,0-13,0$ & $360,435,450$ \\
\hline 4 & $\begin{array}{l}\text { 9-alfa-fluor-18-nor-17,17-dimetilandrostan-4,13- } \\
\text { dieno-11-beta-ol-3-ona }\end{array}$ & 12,059 & & $208,357,462$ \\
\hline 5 & 17-alfa-metil-5-beta-androstano-3-alfa-17-beta-diol & 12,087 & & $360,435,450$ \\
\hline 6 & Epitestosterona & 12,158 & & 417,432 \\
\hline 7 & Testosterona & 12,856 & & 417,432 \\
\hline 8 & Metenolona & 13,340 & $13,0-13,9$ & $195,208,446$ \\
\hline 9 & 17-alfa-etil-5-beta-estrano-3-alfa-17-beta-triol & 13,368 & & $157,331,421$ \\
\hline 10 & Metiltestosterona (padrão interno) & 14,237 & $13,9-14,4$ & 301 \\
\hline 11 & Oxandrolona & 14,650 & $14,4-16,5$ & $308,321,363$ \\
\hline 12 & $\begin{array}{l}\text { 9-alfa-fluor-17-alfa-metil-4-androsteno-3-alfa- } \\
\text { 6-beta-11-beta-tetrol }\end{array}$ & 15,305 & & $462,552,642$ \\
\hline 13 & Oximesterona & 15,931 & & $389,519,534$ \\
\hline 14 & 3-hidroxiestanozolol & 17,070 & $16,5-19,3$ & $254,545,560$ \\
\hline 15 & 16-beta-hidroxiestanozolol & 17,725 & & $218,545,560$ \\
\hline
\end{tabular}

$\mathrm{TR}=$ Tempo de retenção. 


\section{Linearidade}

A correlação entre a resposta obtida e a concentração nominal de testosterona e epitestosterona foi realizada a partir de 3 replicatas das concentrações de 10 (LQ), $30,50,80,100$ e $200 \mathrm{ng} / \mathrm{mL}$, sob as quais foi aplicado o método estatístico de regressão linear ponderada $\left(1 / \mathrm{x}^{2}\right)$. Valores de coeficiente de correlação $\left(\mathrm{r}^{2}\right)$ superiores a 0.99 foram considerados adequados.

\section{Precisão intra e interensaio}

Para a precisão intra-ensaio foi realizada a análise, em um mesmo dia, de seis replicatas de amostras de urina adicionadas de solução padrão dos esteroídes anabólicos em concentrações iguais a 3 vezes o limite de detecção, e, de testosterona e epitestosterona em concentrações de 20,90 e $150 \mathrm{ng} / \mathrm{mL}$, adicionadas do padrão interno. A precisão interensaio foi estabelecida da mesma forma que a precisão intra ensaio, porém realizada em três dias consecutivos. Os coeficientes de variação $(\mathrm{CV})$ foram obtidos através do método estatístico da Análise de Variância (Bressolle, Bromet-Petit, Audram, 1996). Considerou-se adequados valores de CV inferiores a $15 \%$.

\section{Inexatidão intra e interensaios}

Para avaliar a concordância entre o valor determinado e o valor real, foram analisadas amostras de urina nas concentrações de 20,90 e $150 \mathrm{ng} / \mathrm{mL}$ de testosterona e epitestosterona, em triplicata, realizadas em um dia (intra-ensaio) e em três dias consecutivos (interensaio). Considerou-se que o desvio não deveria ser superior a $15 \%$.

\section{Recuperação}

A recuperação foi realizada com três replicatas de amostras de urina adicionadas das soluções padrão dos esteróides anabólicos em concentrações iguais a 3 vezes o limite de detecção para os esteróides anabólicos. Para testosterona e epitestosterona foram utilizadas as concentrações referentes às concentrações de 20, 90 e 150 ng/ $\mathrm{mL}$. Em paralelo, mais três replicatas foram analisadas, porém com a adição dos padrões, posteriormente a etapa de extração para cada concentração referida. A recuperação foi avaliada através da comparação entre as razões de áreas das amostras em que os padrões foram adicionados anteriormente a extração, com aqueles adicionados posteriormente.

\section{Estabilidade}

Foi avaliada a estabilidade da amostra, adicionada dos padrões dos esteróides anabólicos, congelada $\mathrm{a}-20^{\circ}$ $\mathrm{C}$ por 5 dias consecutivos. Amostras, adicionadas de padrões de esteróides, foram submetidas a três ciclos de congelamento e descongelamento (em temperatura ambiente), em três dias consecutivos.

Foram avaliadas para cada modalidade de estabilidade cinco amostras de concentração igual a 3 x LD para todos os esteróides anabólicos. Os dados de razão de área da média das amostras submetidas ao ensaio de estabilidade foram comparadas com a média da razão de área de três amostras recém preparadas, de igual concentração.

Neste estudo também foi avaliada a estabilidade do extrato derivado, que permaneceu por um período de 12 horas à temperatura ambiente.

\section{RESULTADOS}

A Tabela II apresenta os parâmetros de confiança do método validado (LD, precisão intra e interensaios, recuperação) para análise dos esteróides anabólicos e/ ou seus produtos de biotransformação. Para a análise quantitativa de testosterona e epitestosterona, os parâmetros de validação estão apresentados na Tabela III.

A linearidade da curva de calibração para a quantificação de testosterona e epitestosterona foi obtida entre 10 (LQ) e $200 \mathrm{ng} / \mathrm{mL}$. As equações referentes as regressões lineares ponderadas $\left(1 / \mathrm{x}^{2}\right)$ e os coeficientes de correlação foram, respectivamente: $0,034173 \mathrm{x}-0,06596$ $\left(r^{2}=0.99948\right)$ e $0,021763 x-0,04669\left(r^{2}=0,99963\right)$.

Neste trabalho, os dois ensaios de estabilidade (estabilidade da amostra e estabilidade do extrato derivado) apresentaram dados de variação inferiores a $15 \%$ para todos os esteróides estudados, nas condições preconizadas.

Os resultados das análises das amostras de voluntários que relataram uso de esteróides androgênicos anabólicos estão apresentados na Tabela IV. Verifica-se a prevalência de uso de estanozolol pela detecção de seus produtos de biotransformação na urina (3-hidroxiestanozolol e 16-beta-hidroxiestanozolol).

Na Figura 1 é apresentado o perfil cromatográfico da análise de uma amostra de urina de um indivíduo adulto, do sexo masculino, não usuário de esteróides anabólicos. Nesta Figura, os picos relativos à androsterona e à etiocolanolona (metabólitos da testosterona) são bem proeminentes (abundâncias superiores a 220.000) e observa-se a presença de concentrações semelhantes de testosterona e epitestosterona (razão T/E próxima de 1). 
TABELA II - Parâmetros de confiança do método para a análise qualitativa por CG-EM dos esteróides anabólicos e/ ou seus produtos de biotransformação

\begin{tabular}{ccccc}
\hline $\begin{array}{c}\text { Esteróides } \\
\text { anabólicos* }\end{array}$ & $\begin{array}{c}\text { Limite de detecção } \\
(\mathbf{n g} / \mathbf{m L})\end{array}$ & $\begin{array}{c}\text { Precisão intra ensaio } \\
(\mathbf{\%})\end{array}$ & $\begin{array}{c}\text { Precisão inter ensaio } \\
(\mathbf{\%})\end{array}$ & $\begin{array}{c}\text { Recuperação } \\
(\%)\end{array}$ \\
\hline 1 & 1,5 & 10,0 & 3,9 & 91,0 \\
2 & 2 & 5,0 & 2,1 & 96,0 \\
3 & 5 & 10,5 & 4,7 & 104,0 \\
4 & 5 & 3,0 & 1,3 & 82,5 \\
5 & 10 & 10,2 & 3,3 & 84,0 \\
8 & 5 & 8,2 & 10,5 & 101,6 \\
9 & 5 & 6,7 & 3,0 & 94,0 \\
11 & 2 & 8,6 & 4,9 & 93,0 \\
12 & 10 & 7,2 & 3,2 & 41,7 \\
13 & 0,5 & 9,1 & 3,8 & 93,0 \\
14 & 15 & 9,1 & 4,1 & 96,0 \\
15 & 15 & 7,6 & 2,4 & 26,0 \\
\hline
\end{tabular}

*Os números dos esteróides anabólicos se referem à Tabela I.

TABELA III - Parâmetros de confiança do método para a análise quantitativa por CG-EM dos esteróides anabólicos testosterona e epitestosterona

\begin{tabular}{lcc}
\hline & Testosterona & Epitestosterona \\
\hline Limite de Quantificação $(\mathrm{ng} / \mathrm{mL})$ & 10,0 & 10,0 \\
Precisão intra-ensaio (CV\%) & & \\
$20 \mathrm{ng} / \mathrm{mL}$ & 2,3 & 5,4 \\
$90 \mathrm{ng} / \mathrm{mL}$ & 6,7 & 6,5 \\
$150 \mathrm{ng} / \mathrm{mL}$ & 1,7 & 1,5 \\
Precisão interensaio (CV\%) & & 3,2 \\
$20 \mathrm{ng} / \mathrm{mL}$ & 2,0 & 5,4 \\
$90 \mathrm{ng} / \mathrm{mL}$ & 1,0 & 3,2 \\
$150 \mathrm{ng} / \mathrm{mL}$ & 1,5 & \\
Inexatidão intra-ensaio (\%) & & $-0,8$ \\
$20 \mathrm{ng} / \mathrm{mL}$ & $-0,6$ & $-6,3$ \\
$90 \mathrm{ng} / \mathrm{mL}$ & $-4,4$ & $-13,0$ \\
$150 \mathrm{ng} / \mathrm{mL}$ & $-11,6$ & \\
Inexatidão interensaio (\%) & & $-6,9$ \\
$20 \mathrm{ng} / \mathrm{mL}$ & $-3,5$ & $-9,2$ \\
$90 \mathrm{ng} / \mathrm{mL}$ & $-8,1$ & 11,6 \\
$150 \mathrm{ng} / \mathrm{mL}$ & 8,4 & 83,5 \\
\hline
\end{tabular}

As Figuras 2 e 3 apresentam os cromatogramas obtidos por CG-EM das amostras de urina, respectivamente, de um indivíduo usuário do esteróide anabólico testosterona $\left(\right.$ Durateston $\left.^{\circledR}\right)$ com razão T/E superior a 6 e de um indivíduo usuário de estanozolol (Winstrol ${ }^{\circledR}$ ), apresentado uma abundância inferior a 100.000 para os produtos de biotransformação da testosterona.

\section{DISCUSSÃO}

Na maioria dos métodos cromatográficos empregados para detectar EAA, amostras de urina são submetidas à hidrólise enzimática diretamente ou após o procedimento de extração em fase sólida. Em seguida, os analitos são extraídos por extração líquido-líquido em 
TABELA IV - Resultados das análises por GC-MS de amostras de voluntários que relataram uso de esteróides androgênicos anabólicos

\begin{tabular}{cl}
\hline Voluntário & Resultado da análise de esteróides androgênicos anabólicos \\
1 & 3-hidroxiestanozolol e 16-beta-hidroxiestanozolol \\
2 & 3-hidroxiestanozolol e 16-beta-hidroxiestanozolol \\
3 & 3-hidroxiestanozolol e 16-beta-hidroxiestanozolol \\
4 & 3-hidroxiestanozolol e 16-beta-hidroxiestanozolol \\
5 & Relação $\mathrm{T} / \mathrm{E}=16,9$ \\
6 & Relação $\mathrm{T} / \mathrm{E}=16,4$ e metenolona \\
7 & 3-hidroxiestanozolol e 16-beta-hidroxiestanozolol \\
8 & 3-hidroxiestanozolol e 16-beta-hidroxiestanozolol \\
9 & 3-hidroxiestanozolol e 16-beta-hidroxiestanozolol \\
10 & Relação $\mathrm{T} / \mathrm{E}=8,8 ;$ 3-hidroxiestanozolol e 16-beta-hidroxiestanozolol \\
\hline
\end{tabular}

$\mathrm{T} / \mathrm{E}=$ Testosterona/Epitestosterona

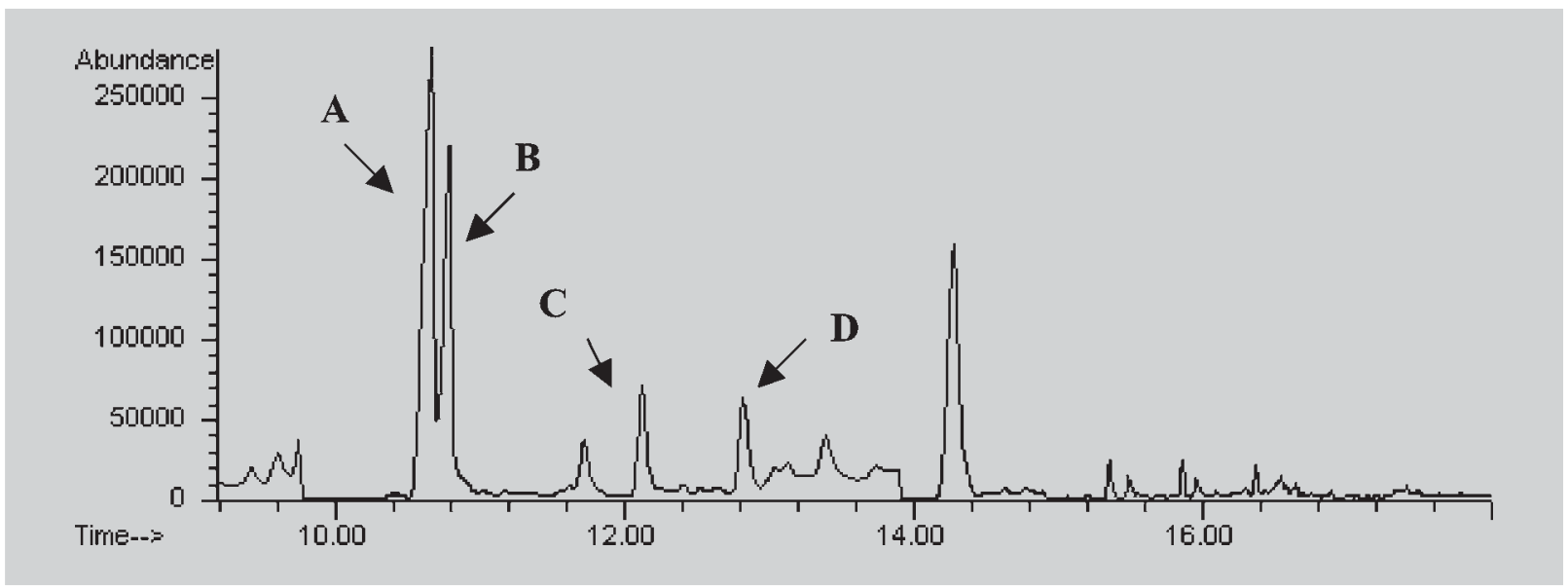

FIGURA 1 - Perfil cromatográfico da análise de uma amostra de urina de um indivíduo adulto, do sexo masculino, não usuário de esteróides anabólicos. Sendo, A - androsterona, B - etiocolanolona, C - epitestosterona, D - testosterona.

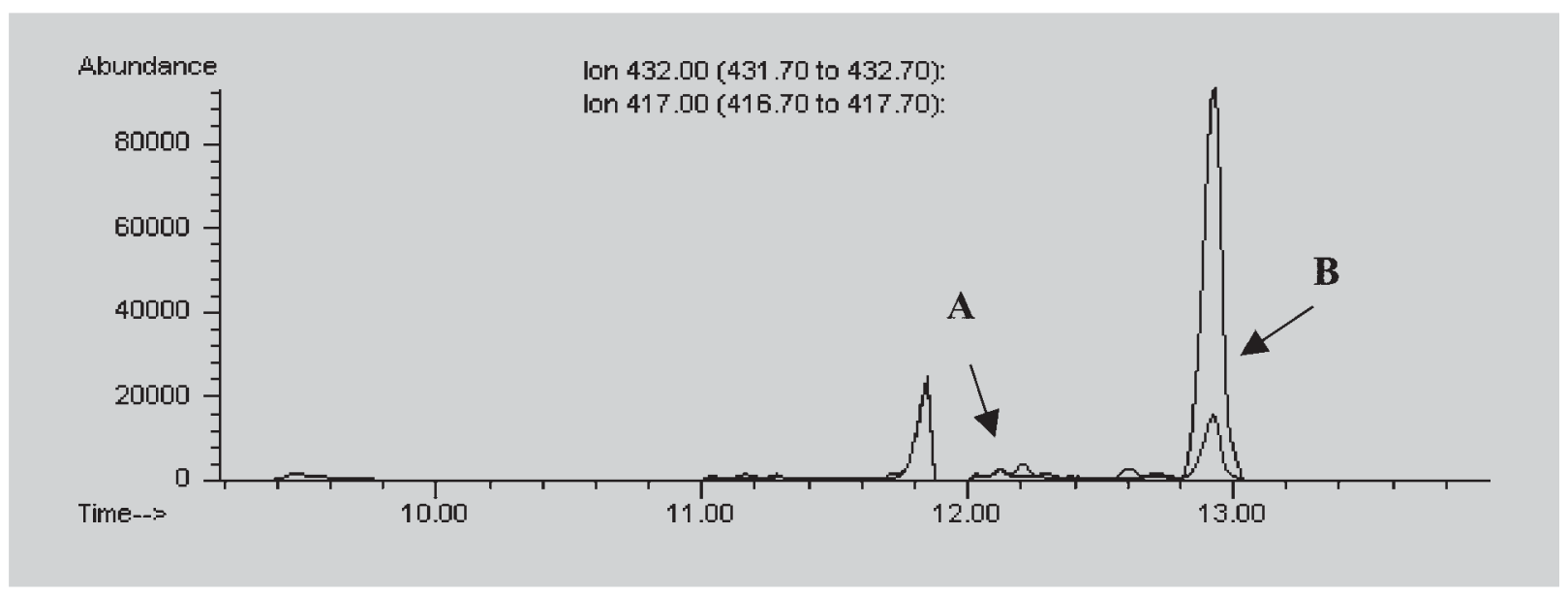

FIGURA 2 - Perfil cromatográfico da análise de uma amostra de urina de um indivíduo adulto, do sexo masculino, usuário de ésteres de testosterona $\left(\right.$ Durateston $\left.^{\circledR}\right)$. Sendo A - epitestosterona, B - testosterona. 


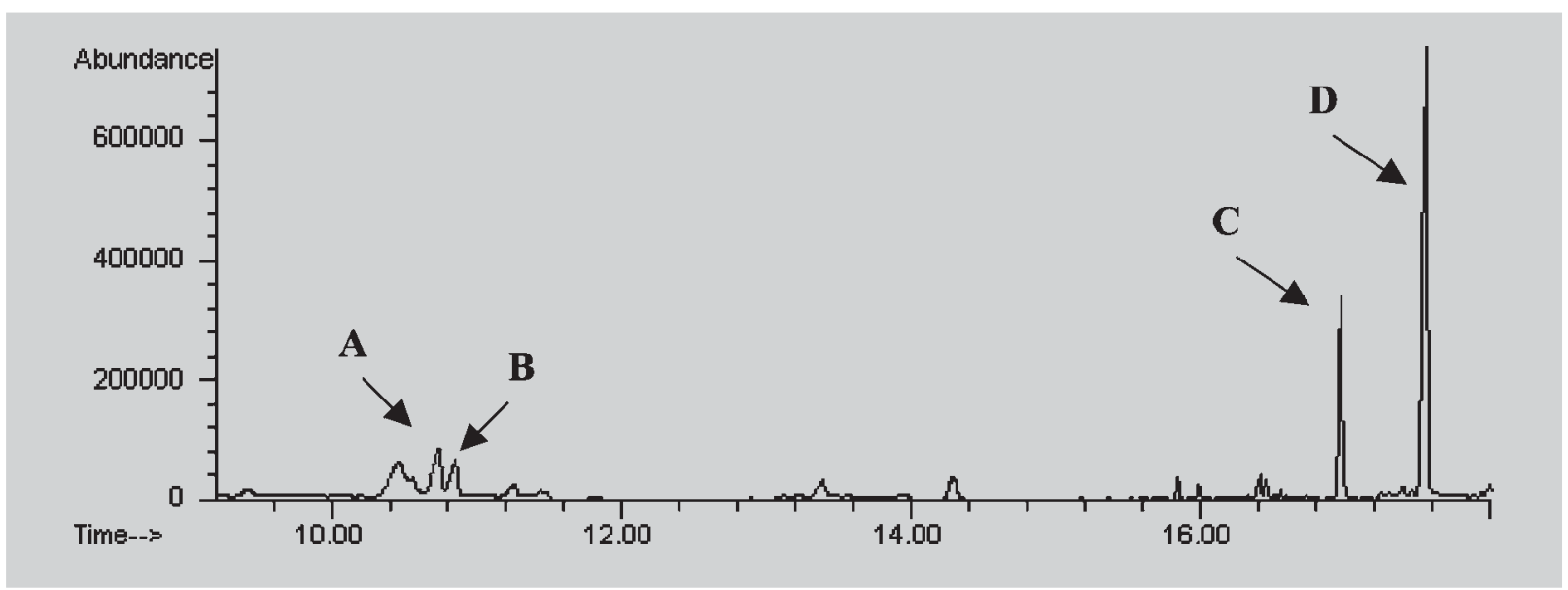

FIGURA 3 - Perfil cromatográfico da análise de uma amostra de urina de um indivíduo adulto, do sexo masculino, usuário de estanozolol $\left(\right.$ Winstrol $^{\circledR}$ ). Sendo A - androsterona, B - etiocolanolona, C - 3-hidroxiestanozolol. D - 16-betahidroxiestanozolol.

meio alcalino (Schanzer, Donike, 1993; Ayotte, Goudreault, Chanlebois, 1996; Özer, Temizer, 1997; Schanzer, 1998; Yoon, Lee, 2001; Marcos et al., 2002). $\mathrm{Na}$ extração em fase sólida, a resina XAD-2 e colunas C-18 são as mais utilizadas (Özer, Temizer, 1997; Yoon, Lee, 2001). No presente trabalho, optamos pela realização de extração líquido-líquido após a hidrólise, por ser mais simples e representar um custo menor em relação à extração em fase sólida. $\mathrm{Na}$ extração líquido-líquido, o solvente mais utilizado é o dietil-éter. Porém, devido à sua alta volatilidade e necessidade periódica de destilação para eliminação de peróxidos, o éter- $t$ butilmetílico foi preferencialmente utilizado, visto que não permite a formação de peróxidos e possui capacidade extratora semelhante (Schanzer, 1998).

As Tabelas II e III demonstram que o método analítico validado apresenta-se preciso e sensível para a análise quantitativa e qualitativa dos principais esteróides anabólicos androgênicos utilizados no âmbito esportivo (Jiménez, Ventura, Segura, 2002; Bressolle, Bromet-Petit, Audram, 1996). O parâmetro linearidade foi avaliado por meio de uma regressão linear ponderada $\left(1 / x^{2}\right)$, visto que foi considerada a existência de heteroscedasticidade ("Goodness-of-fit") dos dados residuais (Sadray, Rezace, Rezakhah, 2003), devido ao amplo intervalo de concentrações dos calibradores utilizados (10-200 ng/mL).

A análise para caracterização da dopagem geralmente não é quantitativa, pois o significado do valor de concentração urinária proveniente de uma coleta única é limitado. Entretanto, para algumas substâncias, existem valores de referências estipulados pelo COI que definem quando o resultado deve ser considerado positivo ou nega- tivo. No caso da testosterona, o limite tem por base a relação de concentração de testosterona/epitestosterona ( $\mathrm{T} /$ E) na urina. Um valor de T/E maior que 6 sugere o uso de testosterona pelo atleta (Van de Kerkhof et al., 2000). Desta forma, para essas substâncias, foi necessário fazer análise quantitativa.

Os dados obtidos nos ensaios de estabilidade permitem inferir que os esteróides anabólicos avaliados permanecem inalterados na amostra biológica quanto submetidos a temperaturas de $-20^{\circ} \mathrm{C}$, ambiente e ao ciclos de congelamento e descongelamento. Essas condições de temperatura e o período de estudo (5 dias) simulam as situações de cadeia de custódia (coleta, transporte e armazenamento da amostra) e análise de prova e contraprova preconizadas pelo COI e outras federações esportivas. Além disso, o estudo de estabilidade do extrato derivado permitiu concluir que as amostras podem ser injetadas após permanecer em temperatura ambiente por um período de até doze horas.

A derivação dos esteróides anabólicos com MSTFA à temperatura de $80{ }^{\circ} \mathrm{C}$ por 120 minutos, bem como a temperatura inicial do forno do cromatógrafo de $120^{\circ} \mathrm{C}$, próximos da temperatura de vaporização do agente de derivação (MSTFA - p.e $=130{ }^{\circ} \mathrm{C}$ ), forneceu características cromatográficas adequadas, como por exemplo os valores LD e LQ, que corroboram os dados recentes da literatura internacional (Haber et al., 2001; Huenerbein, Marques, Neto, 2003).

As Figuras 2 e 3 evidenciam a aplicabilidade do método na caracterização do uso de esteróides anabólicos pelos sujeitos de pesquisa analisados. Neste método, a constatação do uso pôde ser verificada não somente pela identificação dos esteróides e/ou seus 
produtos de biotransformação, mas também pelas alterações do perfil cromatográfico das amostras biológicas analisadas. Assim, observou-se a detecção de baixas abundâncias dos metabólitos de testosterona (androsterona e etiocolanolona) em usuários de estanozolol. Esses dados corroboram os estudos realizados por Alen, Rahkila, Reinila (1987), Norli et al., (1995) e Marques, Pereira, Neto (2003), onde são reportados que esse esteróide exógeno promoveria a supressão do eixo hipotalâmico-hipofisário e conseqüentemente a diminuição dos níveis de testosterona, seus precursores e seus metabólitos.

\section{CONCLUSÕES}

O método validado por CG-EM descrito nesse trabalho cumpre com os princípios de confiança necessários para a detecção de esteróides anabólicos androgênicos em amostras de urina com a finalidade de controle de dopagem no esporte. Nas amostras de urina de voluntários analisadas detectou-se a presença dos principais esteróides androgênicos anabólicos utilizados com finalidade ergogênica no meio esportivo no Brasil (Moreau, Silva, 2003; Lobo et al., 2003).

\section{ABSTRACT \\ Detection of androgenic anabolic steroids (AAS) in urine samples by gas chromatography-mass spectrometry}

Androgenic anabolic steroids (AAS) are defined as natural, synthetic or semi-synthetic drugs chemically derived from testosterone, used with the aim to improve physical performance by increasing both muscle strength and mass. Despite their reported toxicological effects on the cardiovascular, hepatic and neuro-endocrine systems, the AAS have been extensively used in sports activities. The objective of this study was to validate an analytical method for the detection of AAS and/or their metabolites in urine samples. The method was based on enzymatic hydrolysis, liquid-liquid extraction, derivatization and further analysis by gas chromatography-mass spectrometry (GC-MS) operated in the selected ion monitoring mode (SIM). The validated method agrees with the confidence concepts for AAS detection in urine samples for anti-doping control programs. The limits of detection of AAS varied from 0,5 to $15 \mathrm{ng} / \mathrm{mL}$. Good inter and intra-assay precisions were also observed $(C V<11 \%)$. Urine samples collected from volunteers $(n=10)$ who reported AAS use were submitted to the method and the most used AAS in Brazil were successfully detected.

UNITERMS: Androgenic anabolic steroids. Doping. Gas chromatography-mass spectrometry.

\section{REFERÊNCIAS BIBLIOGRÁFICAS}

ALEN, M.; RAHKILA, P.; REINILA, M. Androgenic anabolic steroid effects on serum thyroid, pituitary and steroid hormones in a athletes. Am. J. Sport. Med., Baltimore, v.15, n.4,p.357-361, 1987.

ANVISA. Agência Nacional de Vigilância Sanitária. Resolução RE 899, de 29 de maio de 2003. Guia para Validação de Métodos Analíticos. Disponível em: http:/ /www.anvisa.gov.br . Acesso em: 11 de mar 2005.

AYOTTE, C.; GOUDREAULT, D.; CHANLEBOIS, A. Testing for natural and synthetic anabolic agents in human urine. J. Chromatogr., Amsterdam, v.687, p.3-25, 1996.

BRESSOLLE, F.; BROMET-PETIT, M.; AUDRAM, M. Validation of liquid chromatographic and gas chromatographic methods. Applications to pharmacokinetics. J. Chromatogr. B., Amsterdam, v.686, p.3-10, 1996

CASTILHO, E. G.; NASCIMENTO, E. S. Aspectos analíticos do controle da dopagem de agentes anabolizantes em urina de atletas: avaliação de critérios de positividade. Rev. Bras. Cienc. Farm., São Paulo, v.39, n.1, p. 41-53, 2003.

DE LUiS, D. A.; ALleR, R.; CUEllaR, L. A. Anabolizantes esteroideos y ginecomastia. Revisión de la literatura. Am. Med. Intern., Philadelphia, v.18, n.9, p.489491,2001

DE ROSE, E. H., NÓBREGA, A. C. L. Uso de doping no esporte de alto rendimento. In: AMATUZZI, M. M., CARAZZATO, J. G. Medicina do esporte. São Paulo: Roca, 2004. p.158-171.

DELBEKE, F. T.; DESMET, N.; DEBACKERE, M. The abuse of doping agents in competing body builders in Flanders (1988-1993). Int. J. Sports. Med., Stuttgart, v.16,p.66-70, 1995 
HABER, E.; MUNÕZ-GUERRA, J. A.; SORIANO, C.; CARRERAS, D. Automated sample preparation and gas chromatographic-mass spectrometric analysis of urinary androgenic anabolic steroids. J. Chromatogr. B, Amsterdam, v.755, p.17-26, 2001

HUENERBEIN, A.; MARQUES, M.A.S.; NETO, F. R. A. Improvement in steroid screening for doping control with special emphasis on stanozolol. J. Chromatogr. A, Amsterdam, v.985, p.375-389, 2003.

HURLEY, B. F.; SEALS, D. R.; EHSANI, A. A. Effects of high-intensity strength training on cardiovascular function. Med. Sci. Sports. Exerc., Madison, v.16, p. 483-488, 1984.

JIMÉNEZ, C.; VENTURA, R.; SEGURA, J. Validation of qualitative chromatographic methods: strategy in antidoping control laboratories. J. Chromatogr. B., Amsterdam, v.767, p. 341-351, 2002

KICMAN, A. T.; GOWER, D. B. Anabolic steroids in sports: biochemical, clinical and analytical perspectives. Ann. Clin. Biochem., London, v.40, p. 321-356, 2003

LENDERS, J. W. M; DEMACKER, P. N. M.; HORTSMAN, A. J.; THIEN, T. Deleterious effects of anabolic steroids on serum lipoproteins, blood pressure, and liver function in amateur body builders. Int. J. Sports. Med., Stuttgart, v.9, p.19-23, 1988.

LOBO, A. P. T.; NAPPO, S. A.; SANCHEZ, Z. V. D.; CARLINI, E. A. O uso indevido de anabolizantes na cidade de São Paulo: um estudo qualitativo. J. Bras. Psiquiatr., Rio de Janeiro, v.1, p.25-34, 2003.

MARCOS, J.; PASCUAL, J.A.; DE LA TORRE, X., SEGURA J. J. Mass. Spectrom., v.37, p.1059-1073, 2002.

MARQUES, M. A. S.; PEREIRA, H. M. G.; NETO, F. R. A. Controle de dopagem de anabolizantes: o perfil esteroidal e suas regulações. Rev. Bras. Med. Esporte, São Paulo, v.9, n.1, p.15-24, 2003.

MOREAU, R. L. M.; SILVA, L. S. M. F. Uso de esteróides anabólicos androgênicos por praticantes de musculação de grandes academias da cidade de São Paulo. Rev. Bras. Cienc. Farm., São Paulo, v.39, n.3, p.327-333, 2003.
NORLI, H. R.; ESBENSEN, K.; WESTAD, F.; BRIKELAND, K. I.; HEMMERSBACH, P. Chemometric evaluation of urinary steroid profiles in doping control. J. Steroid Biochem. Molec. Biol., Oxford, v.54, n.1/2, p.83-88, 1995.

OZER, D.; TEMIZER, A. The determination of nandrolone and its metabolites in urine by gas chromatography-mass spectrometry. Eur. J. Drug. Metab. Pharmacokinet., Paris, v.22, n.4, p.421-425, 1997.

PARSSINEN, M.; SEPPALA, T. Steroid use and long-term health risks in former athletes. Sports Med., Auckland, v.32, n.2, p.83-94, 2002

SADRAY, S.; REZACE, S.; REZAKHAH, S. Non-linear heteroscedastic regression model for determination of methotrexate in human plasma by high-performance liquid chromatography. J. Chromatogr. A., Amsterdam, v.787, p.293-302, 2003

SILVA, O. A.; YONAMINE, M. Aspectos farmacológicos da dopagem no esporte. In: AMATUZZI, M. M., CARAZZATO, J. G. Medicina do esporte. São Paulo: Roca, 2004. p.141-157.

SCHANZER, W. Detection of exogenous anabolic androgenic steroids. In: KARCH, S.B. Drug abuse handbook. Boca Raton: CRC Press, 1998. p.671-689.

SCHANZER, W.; DONIKE, M. Metabolism of anabolic steroids in man: synthesis and use of reference substances for identification of anabolic steroid metabolites. Anal. Chim. Acta., Amsterdam, v.275, p.23-48, 1993.

TORRES-CALLEJA, J.; GONZALEZ-UNZAGA, M.; PEDRÓN, N. Effect of androgenic anabolic steroids on sperm quality and serum hormone levels in adult male bodybuilders. Life Sci., Elmsford, v.68, p.1769-1774, 2001.

URHAUSEN, A.; TORSTEN, A.; WILFRIED, K. Reversibility of the effects on blood cells, lipids, liver function and hormones in former anabolic androgenic steroid abusers. J. Steroid. Biochem. Mol. Biol., Oxford, v.84,p.369-375, 2003

VAN DE KERKHOF, D. H.; DE BOER, D.; THIJSSEN, J. H. H.; MAES, R. A. A. Evaluation of testosterone/ epitestosterone ratio influential factors as determined in doping analysis. J. Anal. Toxicol., Niles, v.24, p. 102-115, 2000. 
WORLD ANTI-DOPING AGENCY (WADA). The world anti-doping code. International Standard for Laboratories. Version 3.0, 2003a, 53p. Disponível em http://www.wada-ama.org/rtecontent/document/ testing_v3_a.pdf. Acesso em: 11 de mar 2005.

WORLD ANTI-DOPING AGENCY (WADA). WADA Technical Document - TD2003IDCR, 2003b, 5p. Disponível em http://www.wada-ama.org/rtecontent/ document/criteria_1_2.pdf. Acesso em: 11 de mar 2005.
YESALIS, C. E. Anabolic in sports and exercises. 2 ed. Champaign: Human Kinetics, 2000, 439p.

YOON, J.M.; LEE, K.H. Gas chromatographic and mass spectrometric analysis of conjugated steroids in urine. $J$. Biosci., Osaka, v.26, n.5, p.627-634, 2001.

Recebido para publicação em 11 de novembro de 2004. Aceito para publicação em 26 de março de 2005. 